TI 2011-045/3

Tinbergen Institute Discussion Paper

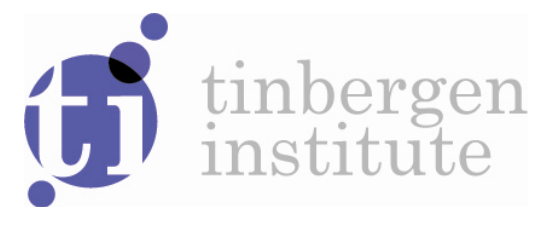

Unobserved Heterogeneity and Risk in Wage Variance:

Does Schooling Provide Earnings Insurance?

Jacopo Mazzas

Hans van Ophems

Joop Hartogs *

\& University of Amsterdam;

* Tinbergen Institute. 
Tinbergen Institute is the graduate school and research institute in economics of Erasmus University Rotterdam, the University of Amsterdam and VU University Amsterdam.

More TI discussion papers can be downloaded at http://www.tinbergen.nl

Tinbergen Institute has two locations:

Tinbergen Institute Amsterdam

Gustav Mahlerplein 117

1082 MS Amsterdam

The Netherlands

Tel.: +31(0)205251600

Tinbergen Institute Rotterdam

Burg. Oudlaan 50

3062 PA Rotterdam

The Netherlands

Tel.: +31(0)10 4088900

Fax: +31(0)104089031

Duisenberg school of finance is a collaboration of the Dutch financial sector and universities, with the ambition to support innovative research and offer top quality academic education in core areas of finance.

DSF research papers can be downloaded at: http://www.dsf.nl/

Duisenberg school of finance

Gustav Mahlerplein 117

1082 MS Amsterdam

The Netherlands

Tel.: +31(0)20 5258579 


\title{
Unobserved Heterogeneity and Risk in Wage Variance: Does Schooling Provide Earnings Insurance?
}

\author{
Jacopo Mazza ${ }^{1}$ Hans van Ophem ${ }^{\S}$ Joop Hartog ${ }^{\S}$
}

February 2011

\begin{abstract}
We apply a recently proposed method to disentangle unobserved heterogeneity from risk in returns to education. We replicate the original study on US men and extend to US women, UK men and German men. Most original results are not robust. A college education cannot universally be considered an insurance against unpredictability of wages. One conclusion is unequivocally confirmed: uncertainty strongly dominates unobserved heterogeneity.
\end{abstract}

JEL classifications: C01, C33, C34, J31

Keywords: wage inequality, wage uncertainty, unobserved heterogeneity, selectivity, education, replication

\footnotetext{
${ }^{1}$ Corresponding author. Universiteit van Amsterdam, Address: Universiteit van Amsterdam, Roetersstraat 11, 1018 WB Amsterdam, The Netherlands, E-mail: j.mazza@uva.nl.

${ }^{\S}$ Universiteit van Amsterdam.

All data and computer programs are available on request.
} 


\section{Introduction}

Benefits from schooling are uncertain. Going to school may either increase or decrease earnings risk. Realised earnings variances for individuals with given levels of schooling are well documented, but such data are not informative on risk as they also include unobserved heterogeneity that may govern potential students' choice $^{2}$. Empirical information on the extent of risk in schooling choice is very important. With uncertain schooling benefits a fact of life, we need to know the extent of risk as an input for realistically modeling schooling choice as a choice under risk (Levhari and Weiss, 1974). Knowing the extent of risk is particularly relevant for policy issues. Education is often promoted as an insurance against the vagaries of the labour market (or even life) but the argument only holds if indeed continued education reduces risk; we have no solid evidence that it does.

A recent paper by Chen (2008) recognizes the potential bias in ex post earnings data and suggests a method to correct for it. She claims two major contributions. The first is the identification of the causal relation between education and inequality. The second is the decomposition of wage inequality between uncertainty and unobserved heterogeneity ${ }^{3}$. We considered Chen's method a sufficiently promising approach to learn about the relationship between schooling and risk and we decided to apply it to data from different countries, in search of reliable and robust empirical information.

As a natural check on reliability of Chen's result and on correct application of her method, we will replicate her estimation on the original population. Economists often praise the virtue of replication, but rarely attempt it. We strongly believe that putting empirical results under careful scrutiny is an important if not essential task per se. Hamermesh (2007) defines pure replication as examining the same question and model using the underlying original data set and scientific replication as the same type of research on different sample and different population. The present work covers both aspects. Our results underscore the value of both types of replication.

Chen reports two main conclusions. First, risk does not increase with educational level as previous research on the topic suggested. Second, she finds evidence of pervasive underestimation of potential wage differences by observed wages inequalities. Our estimations on the same sample and population do not confirm these findings. On one hand,

\footnotetext{
${ }^{2}$ Realised earnings variance has no robust relationship with length of education: depending on time and country, it may increase, decrease or stay constant. See Hartog, Van Ophem and Bajdechi (2004) and Raita (2005).

${ }^{3}$ A different method to reach the same goal has been proposed by Cunha, Heckman and Navarro (2005). Also Belzil and Leonardi (2007) take endogeneity into account to establish how risk aversion is affecting educational choices.
} 
we find that risk does increase, for every level after high school. On the other hand, we obtain a theoretically unexpected underestimation of potential inequality by observed inequality. We cannot locate the exact cause for these deviations, as exact replication was prohibited by US data disclosure regulation and by obscurities in Chen's report ${ }^{4}$.

British data do not confirm our results and are neither in conformity with Chen's original results. In fact, risk decreases by schooling level while for only three out of six educational categories we encounter the expected positive ratio of potential/observed wage variability. With German data, we find correlations coefficients outside the permitted interval: the model simply does not apply to these data. We must conclude that the relationship between level of schooling and risk is far from settled.

We proceed as follows. In section II we set forth Chen's model, in Section III we discuss the data and in Section IV we present the replication results. In Section V we apply the model to American women, in Section VI to men in the UK and in Section VII to men in Germany. Section VIII concludes.

\section{Chen's model}

\section{A. The theoretical model}

The model in Chen (2008) has been constructed to exploit the data in the NLSY79. Consider a panel dataset of $N$ workers observed over $T$ time periods indexed by subscripts $i$ and $t$ respectively. In the first period worker i's schooling level is determined; it will not change over the following periods. The schooling level chosen by the individual will be indicated with $s$. The possible choices in the NLSY79 are four: no high school diploma $\left(s_{i}=0\right)$, high school graduate $\left(s_{i}=1\right)$, some college $\left(s_{i}=2\right)$ and four years college or beyond $\left(s_{i}=3\right)$. $y_{i t}$ indicates the observed $\log$ wage in period $t$ for person $i$. The worker's potential wage is obviously observed only in one educational level, therefore, the worker's observed wage is:

$$
y_{i t}=y_{0 i t} I\left\{s_{i}=0\right\}+y_{1 i t} I\left\{s_{i}=1\right\}+y_{2 i t} I\left\{s_{i}=2\right\}+y_{3 i t} I\left\{s_{i}=3\right\} \text {, }
$$

\footnotetext{
${ }^{4}$ All our doubts and queries raised in the replication have been submitted to Chen. Unfortunately, we have not received any clarification for any of the unclear passages, not even after the editors of REStat supported our requests.
} 
where $I\{\}$ is the indicator function taking value 1 if the subject belongs to that specific schooling category and 0 otherwise. The link between schooling level $s_{i}$ and potential wage $\left(y_{\text {sit }}\right)$ is given by the following regression model:

$$
y_{s i t}=\alpha_{s}+x_{i t} \beta_{s}+\sigma_{s} e_{s i}+\psi_{s t} \varepsilon_{i t} \text { if } s_{i}=S
$$

$\alpha_{s}$ is the intercept for schooling level $s, \beta_{s}$ the vector of coefficients of the observable characteristics $x_{i t}, e_{s i}$ and $\varepsilon_{i t}$ are unit root random variables uncorrelated with each other. The time invariant individual fixed effects are incorporated in $\sigma_{s} e_{s i}$. This term measures the unobserved earning potential at schooling level $s$ which is allowed to be correlated with observable characteristics $x_{i t} . \psi_{s t} \varepsilon_{i t}$ denotes the transitory shock, assumed to be uncorrelated with observables. The potential wage variation is $\sigma_{s}^{2}+\psi_{s t}^{2}$ for subjects' schooling choices $s$ and covariates at time $t$. The permanent component $\sigma_{s}^{2}$ is created by variations in the individual specific effects which are supposed to vary across educations, but to be constant in time. The temporary shocks emerging from macroeconomic conditions or institutional changes are incorporated in $\psi_{s t}^{2}$ which can vary with both time and schooling level. The variables of interest in this model are the variances of both components in potential wages.

The selection problem is formalized in a latent-index schooling assignment rule:

$$
s_{i}=s \text { if } v_{i} \in A_{s} \text { for } s=0,1,2 \text { or } 3 \text {, }
$$

where the unobserved schooling factor $v_{i}$ summarizes the private information such as taste for education, ability and so on, which influences the subjects' educational choices. $A_{s} \equiv\left\{v_{i}: a_{s i} \leq v_{i} \leq a_{s+1, i}\right\}$ is the group of individuals who chose educational level $s$. $a_{s i} \equiv \kappa_{s}-z_{i} \theta$ is the minimal level of the unobserved schooling factor in $A_{s}$. The vector $z_{i}$ contains both covariates $x_{i t}$ and an instrument for education whose coefficients are contained in $\theta . \kappa_{0}=-\infty$ and $\kappa_{4}=\infty$. The structure of error terms is known to all agents and summarized by: 


$$
\left[\begin{array}{l}
e_{s i} \\
\varepsilon_{i t} \\
v_{i}
\end{array}\right] \sim N\left(\left[\begin{array}{l}
0 \\
0 \\
0
\end{array}\right],\left[\begin{array}{ccc}
1 & 0 & \rho_{s} \\
& 1 & 0 \\
& & 1
\end{array}\right]\right) .
$$

As assumed, the unobserved schooling factor is correlated with the individual fixed effects, but not with the transitory shocks $\psi_{s t}$. The correlation coefficient $\left(\rho_{s}\right)$ can assume either positive or negative values. In case of positive value we have positive selection, the opposite in case of negative values.

The parameter $v_{i}$ clarifies why it is important to distinguish between wage variability and risk. In fact, the private information, by definition unobservable to the econometrician, can be used to predict the distribution of potential wages accessible to the subject for each schooling level. The expected value of potential wage at time $t$ and schooling level $s$, from a personal point of view is given by:

$$
E\left[y_{s i t} \mid s_{i}=s, x_{i t}, v_{i}\right]=\alpha_{s}+x_{i t} \beta_{s}+\gamma_{s} v_{i}
$$

where $\gamma_{s} v_{i}$ represents the unobserved heterogeneity component at schooling level $s$ and $\gamma_{s} \equiv \sigma_{s} \rho_{s}$. Equation (5) follows from the distributional assumptions in (4) and $E\left[e_{s i} \mid s_{i}=s, x_{i t}, v_{i}\right]=\rho_{s} v_{i}$.

Since the agent knows his own ability and tastes and uses the information to select the appropriate level of schooling, the degree of wage uncertainty can not exceed the degree of potential wage inequality. The wage uncertainty at schooling level $s$ is measured $b y^{5}$ :

$$
\tau_{s}^{2} \equiv \operatorname{Var}\left[\sigma_{s} e_{s i}+\psi_{s t} \varepsilon_{i t} \mid s_{i}=s, x_{i t}, \nu_{i}\right]=\sigma_{s}^{2}\left(1-\rho_{s}^{2}\right)+\psi_{s t}^{2} \leq \sigma_{s}^{2}+\psi_{s t}^{2} .
$$

The second equality follows from the distributional assumptions described in (4): $\operatorname{Var}\left(e_{s i} \mid s_{i}=s, x_{i t}, v_{i}\right)=1-\rho_{s}^{2}$. This equation makes explicit that potential wage variability $\left(\sigma_{s}^{2}+\psi_{s t}^{2}\right)$ is formed by two components: inequality created by wage uncertainty $\tau_{s t}$ and inequality from unobserved heterogeneity $\gamma_{s}^{2}=\sigma_{s}^{2} \rho_{s}^{2}$. In fact, if we rewrite equation (6) we obtain: $\sigma_{s}^{2}+\psi_{s t}^{2}=\sigma_{s}^{2} \rho_{s}^{2}+\tau_{s}^{2}$ and remembering $\gamma_{s} \equiv \sigma_{s} \rho_{s}$ we see that $\sigma_{s}^{2}+\psi_{s t}^{2}=\gamma_{s}^{2}+\tau_{s}^{2}$.

\footnotetext{
${ }^{5}$ We copy this equation from Chen; it is clear that $\tau$ should be subscripted for time, but Chen ignores this. See also section 3C.
} 
This equation also shows the three sources of uncertainty that each individual has to face: the earnings potential $\sigma_{s}$ of the individual fixed effect $\left(e_{s i}\right)$; correlation between potential wages and private information $\left(\rho_{s}\right)$; transitory shocks due to institutional changes $\left(\psi_{s t}\right)$.

Equations (4) and (5) imply that potential wages are composed of observed heterogeneity $\left(x_{i t} \beta_{s}\right)$, unobserved heterogeneity $\left(\gamma_{s} v_{i}\right)$ and an unforeseeable component $\left(\tau_{s t}\right)$ plus an error term $\left(u_{i t}\right)$

$$
y_{s i t}=\alpha_{s}+x_{i t} \beta_{s}+\gamma_{s} v_{i}+\tau_{s t} u_{i t}
$$

where $u_{i t}$ is a normalized random variable, uncorrelated with observable and unobservable characteristics. $\tau_{s t} u_{i t}$ is called the unforeseeable component of wage residuals, that is to say risk. The first three terms of equation (7) are a direct consequence of the value of potential wage expected (by the individual) as explained in equation (5). The last term is describing uncertainty as modeled in equation (6) corrected by a normally distributed error term.

From this discussion it should be clear that the targets of identification are: wage uncertainty $\left(\tau_{s t}\right)$ and the permanent and transitory component of potential wage inequality $\left(\sigma_{s}^{2}\right.$ and $\left.\psi_{s t}^{2}\right)$.

\section{B. Model estimation and parameter identification}

Equations (5) and (6) can not be used for regression analysis since $v_{i}$ is unobserved; what is observed is the educational choice of an agent. The mean and variance of observed wages are derived by the following equations:

$$
E\left[y_{i t} \mid s_{i}=s ; x_{i t}, z_{i}\right]=E\left[y_{s i t} \mid v_{i} \in A_{s} ; x_{i t}, z_{i}\right]=\alpha_{s}+x_{i t} \beta_{s}+\sigma_{s} \rho_{s} \lambda_{s i}
$$

$\operatorname{Var}\left[y_{i t} \mid s_{i}=s ; x_{i t}, z_{i}\right]=\operatorname{Var}\left[\sigma_{s} e_{s i}+\psi_{s t} \varepsilon_{i t} \mid v_{i} \in A_{s} ; x_{i t}, z_{i}\right]=\sigma_{s}^{2}\left(1-\rho_{s}^{2} \delta_{s i}\right)+\psi_{s t}^{2} \leq \sigma_{s}^{2}+\psi_{s t}^{2}$

These equations specify the requirement for the construction of adjustments for truncation $(\delta)$ and selection $(\lambda)$, explained below. Equation (8) shows that observed wages overstate or 
understate the mean potential wages depending on the sign of the correlation term $\rho_{s}$. The selectivity adjustment $\lambda_{s i}$ is an inverse Mill's ratio:

$$
\lambda_{s i} \equiv E\left[v_{i} \mid v_{i} \in A_{s}\right]=\left[\phi\left(a_{s i}\right)-\phi\left(a_{s+1, i}\right) / \Phi\left(a_{s+1, i}\right)-\Phi\left(a_{s i}\right)\right]
$$

Equation (9) shows how regardless of the sign of selection bias, the observed wages understate the degree of potential wage inequality for each educational level. The degree of understatement is called by Chen truncation adjustment $\left(\delta_{s i}\right)$ :

$$
\delta_{s i} \equiv 1-\operatorname{Var}\left[v_{i} \mid v_{i} \in A_{s}\right]=\lambda_{s i}^{2}-\left[a_{s i} \phi\left(a_{s i}\right)-a_{s+1, i} \phi\left(a_{s+1, i}\right)\right] /\left[\Phi\left(a_{s+1, i}\right)-\Phi\left(a_{s i}\right)\right],
$$

where $\phi$ and $\Phi$ denote standard normal density and distribution function, respectively.

The inclusion of inverse Mill's ratio is not enough if the target of identification is the untruncated variance of wages. For this purpose, a multi-step process is proposed. The first step is to obtain the truncation and selectivity adjustment in the first stage of a Heckman selection model. Then, a fixed-effect model based on equation (8) is estimated and the transitory component $\psi_{s t}^{2}$ identified $^{6}$. The fixed effect model is expressed as:

$$
\left(y_{i t}-\bar{y}_{i}\right)=\left(x_{i t}-\bar{x}_{i}\right) \beta_{s}+\left(\xi_{s i t}-\bar{\xi}_{s i}\right) \text { if } s_{i}=s,
$$

where $\bar{y}_{i}, \bar{x}_{i}$ and $\bar{\xi}_{s i}$ denote the averages over time of the corresponding variables over the survey years.

Next, a between-individuals model identifies the schooling coefficient:

$$
\bar{y}_{i}=\alpha_{s}+\bar{x}_{i} \beta_{s}+\gamma_{s} \lambda_{s i}+w_{i}
$$

The error term $w_{i} \equiv \sigma_{s} u_{s i}+\bar{\varepsilon}_{s i}-\gamma_{s} \lambda_{s i}$ satisfies by construction $E\left[w_{i} \mid s_{i}=s ; \bar{x}_{i}, z_{i}\right]=0$ and $\operatorname{Var}\left[w_{i} \mid s_{i}=s ; \bar{x}_{i}, z_{i}\right]=\sigma_{s}^{2}-\gamma_{s}^{2} \delta_{s i}^{2}+\sum_{t} \psi_{s t}^{2} / T_{i}$. Thus, the consistent estimator for the permanent component of potential wage inequality is:

\footnotetext{
${ }^{6}$ The complete process leading to the identification of the transitory component is discussed in Chen (2008) note 9 p. 278.
} 


$$
\hat{\sigma}_{s}^{2}=\hat{\operatorname{Var}}\left(w_{i} \mid s_{i}=s ; \bar{x}_{i}, z_{i}\right)+\hat{\gamma}_{s}^{2} \overline{\hat{\delta}}-\sum_{t} \hat{\psi}_{s t}^{2} / \bar{T}
$$

The first term of this summation is the mean squared errors of the between-individuals model, whose estimates will be presented in table 4a in section III; the second is the interaction between the consistent estimate of the unobserved heterogeneity term $(\gamma)$ and the sample average of the truncation adjustment $(\overline{\hat{\delta}})$; the third the ratio between the transitory component of wage inequality $\left(\hat{\psi}_{s t}^{2}\right)$ and $\bar{T} \equiv\left(\sum_{i} T_{i}^{-1} / N\right)^{-1}$.

Let's recollect the concepts that have been introduced so far:

- Observed wages $\left(y_{i t} \mid s_{i}=s ; x_{i t}, z_{i}\right)$ : wages observed in the data.

- Potential wages $\left(y_{\text {sit }}\right)$ : wages obtained by individual $i$ if he had chosen schooling level s. Potential wage is the sum of observed heterogeneity $\left(x_{i t} \beta_{s}\right.$ - known to individuals and econometrician); unobserved heterogeneity $\left(\gamma_{s} \nu_{i}\right.$ - known only to the individuals); unforeseeable component ( $\tau_{s t} u_{i t}$ - unknown to everyone).

- Observed wage inequality $\left(\operatorname{Var}\left[y_{i t} \mid s_{i}=s ; x_{i t}, z_{i}\right]\right)$ : within educational category variation in wages. It is decomposed as the sum of transitory volatility $\left(\psi_{s t}^{2}\right.$ estimates shown in panel B and B' of table 4a below) and the mean squared errors of the between individual-model (estimates shown in Panel A of table 4a below).

- Potential wage inequality $\left(\sigma_{s}^{2}+\psi_{s t}^{2}\right)$ : wage inequality that would have been experienced for each educational category if education was not chosen, but randomly assigned. It is the sum of the transitory volatility as defined above $\left(\psi_{s t}^{2}\right)$ and the permanent component $\left(\sigma_{s}^{2}\right)$. The permanent component here accounts for selection and truncation biases (Panels $C$ and D in table $4 b$ ).

- Unobserved heterogeneity $\left(\gamma_{s} v_{i}\right)$ : includes all the characteristics known to the individuals, but unknown to the econometrician that influence the schooling decisions and bias the OLS wage estimates (Panels H and I of Table 4c).

- Wage uncertainty $\left(\tau_{s}^{2}\right)$ : proper measure of risk in educational category $s$, equal to the sum of transitory component as defined above and a permanent component (estimates in Panel G table 4c) accounting for the unobserved schooling factor $v_{i}$. Estimates of wage uncertainty (risk) can be found in Panel H and I in table 4c. 


\section{Data}

Chen's estimates are based on the NLSY: 1979-2000 merged with restricted geocode data. The geocode gives access to detailed information on the residence of respondents; it allows to control for the population density in the county of residence and to construct an instrument: average tuition fees in the county of residence for a public four-year college in the year when the respondent was 17 . We do not have access to the geocode data since their use is limited to researchers at American institutions. We will have to use a different instrument for schooling and we will not be able to control for population density in the area of residence. However, this should have no consequences as long as our instrument serves the same purpose as Chen's instrument. At worst we will experience some loss of efficiency.

Both our and Chen's original sample consist of 12,686 respondents aged 14-22 in 1979. Chen focuses only on males between survey years 1991-2000, which corresponds to calendar years 1990-1999, so that all the respondents should have already terminated their studies. Sampling weights are used to calculate all estimates. Since she does not specify which sampling weights were used, we will apply the standard sampling weights ${ }^{7}$ provided with the NLSY79. She excludes respondents that do not provide any information about parental education or the particular ability index that she utilizes. Following her line of conduct 4930 individuals remain in our sample ${ }^{8}$. We also have to drop 11 individuals who do not have any information on highest grade completed. An additional 228 observations were deleted since it was impossible to retrieve the exact work experience accumulated over the period in consideration. Finally, for as many as 1318 individuals no information on the hourly rate of pay is available. Since this is one of the outcome variables, we had to erase them from our sample. Thus, at this point, our balanced panel sample constitutes of 3373 individuals.

Chen (2008) is not explicit about the exact size of her sample. Her time invariant variables, selected with the above mentioned procedure, have 4302 respondents, 628 individuals less than what we obtained. She also has an unbalanced sample for time variant regressors. For the first year she has 2826 observations. The size constantly diminishes with time, until only 2522 individuals remain in the 1999 sample $^{9}$. It is not clear to us how she obtained those numbers since all the variables she claims to select her sample on are time invariant and the original NLSY79 database has no attrition. She does not provide any

\footnotetext{
${ }^{7}$ The sampling weights used are coded as R3655800, R4006300, R4417400, R5080400, R5165700, R6466300, R7006200 in the NLSY79 for the survey years 1991, 1992, 1993, 1994, 1996, 1998, 2000 respectively.

${ }^{8} 6283$ females, 452 individuals with no information about ability index, 414 individuals with no information about mothers' and 607 about fathers' education were deleted.

${ }^{9}$ Chen (2008) p.280 table 1.
} 
information about sample size used in her first stage regressions. Her wage regressions are based on 3184 respondents and 18245 observations. Thus, apparently, 1118 individuals included in Chen's descriptive statistics that we will present in table 1a have no information about wages.

We follow Chen's data choices as much as we can. Schooling is defined by the highest grade completed according to the 1990 survey when all respondent were at least 25 years old, and measured with four dummy variables: no high school (YOS $<12$ ); high school (YOS=12); some college $(12<\mathrm{YOS}<16)$; college $(\mathrm{YOS} \geq 16)$. The ability index is the Armed Force Qualifying Test (AFQT). It was conducted in 1980 for all respondents of all ages and schooling levels; original scores are regressed on age dummies and quarter of birth and residuals are included in the choice and wage regressions. Quarters of birth capture schooling effects through compulsory schooling laws (Angrist and Krueger (1991). We use hourly pretax earnings, from wages, salary, commissions or tips from all jobs in the calendar year preceding the survey ${ }^{10}$. The family income measure considers family income at age 17 , or as close to 17 as possible. If family income at 17 is unavailable then the measure is taken at 16 or 18 . For nearly half of the respondents the family income measure at age 17 is unavailable ${ }^{11}$. The work experience measure is constructed from the longitudinal work history in the NLSY79. Number of weeks worked in past calendar year are converted in number of full working years by dividing by 49 .

We have to deviate from Chen because we have no access to the geocode data. Chen adds two geographical controls to choice and wage equations: an urban dummy at age 14 and the county of residence population density in 1980, but population density is not available to us. The instrument for schooling in the original paper is the potential college tuition cost at county level defined as the average tuition fees at the local public four-year college in the year when the respondent was 17. This measure also exploits the restricted information on the respondents' county of residence that is not available to us. We instrumented schooling choice with the average unemployment rate differentiated by sex, age group and ethnic origin for the years spent in school after the mandatory schooling age. The intuition behind this instrument

\footnotetext{
${ }^{10}$ Chen (2008) p. 279 claims to use annual earnings. This claim does not correspond with the earnings measure presented in table 1 which is the logarithm of hourly earnings in 1992 dollars. We tried both outcome variables and chose the latter. In fact, if annual earnings were used as dependent variable in the betweenindividuals model, the magnitude of the residuals as presented in table 4 panel I would seem to be too small. This is not the case if hourly earnings are the explained variable used.

${ }^{11}$ As is evident from table $2 \mathrm{a}$ and $2 \mathrm{~b}$, it seems that Chen included four dummies to characterize the entire quartile distribution of family income at age 17. Since it is evident that four dummies plus the constant would create a dummy trap, we suspect that, even if she does not expressly state it in her paper, she created a dummy variable for non response to the family income question. This is the way we proceed.
} 
is that the facility to find a job in the market might influence the outside option of each student. A possible concern using this variable is that unemployment rates during youth might correlate with current unemployment rates and thus wages. We will therefore also include the unemployment rate for the year in which the wage is measured in the wage regressions. The assumption is then that conditional on current unemployment rates in the country, past unemployment rates are uncorrelated with wages earned ${ }^{12}$. The lack of precise geographical location forces us to use the national rate of unemployment for young workers. Data about unemployment rates are taken from the Current Population Survey (CPS) ${ }^{13}$.

The risk of taking such a crude measure of unemployment as the national rate is a weak correlation between the instrument and schooling choices. We will show in the choice equations presented in table $2 \mathrm{a}$ and $2 \mathrm{~b}$ that this concern is misplaced. 195 individuals dropped out of school before the legal mandatory age. Unemployment figures from the CPS are only available for people aged 16 and older. If a respondent dropped out of school before that age no unemployment rate is imputable. Our final sample thus counts 3,178 respondents and 21,573 observations.

In table $1 \mathrm{a}$ and $1 \mathrm{~b}$ we report summary statistics. Our sample differs from the original one $^{14}$ in some aspects. First, it shows a higher number of individuals without a high school education, which reflects in a lower number of high school graduates and college (or more) graduates. Second, the average AFQT score is lower. Last, the share of ethnic minorities, blacks and Hispanics, is considerably higher in our sample. Also, family income is considerably lower. In table $1 \mathrm{~b}$ we can see how our work experience measure is almost constantly one year higher, while the log of hourly earnings is slightly lower. The difference in hourly earnings might be explained by the larger share of high school drop outs and high school graduates that our sample has.

Overall, our sample appears to represent a less educated, more ethnically diversified and poorer share of the population than the one Chen uses for her analysis. This is an unintended difference for which there is no clear explanation. It can influence the results of our estimations as we will see later on.

\footnotetext{
${ }^{12}$ Arkes (2010) and Hausman and Taylor (1981) are two of the very few studies that use unemployment during schooling years as instrument for schooling.

${ }^{13}$ The URL address is: http://data.bls.gov:8080/PDQ/outside.jsp?survey=ln. (Accessed 15/06/2010)

${ }^{14}$ Chen (2008) p. 280.
} 
Table 1a. Mean and standard deviation time invariant variables NLSY79

\begin{tabular}{|c|c|c|}
\hline & Our sample & Chen's sample \\
\hline \multicolumn{3}{|l|}{ (a)Schooling variables } \\
\hline Years of schooling & $\begin{array}{l}12.99 \\
(2.57)\end{array}$ & $\begin{array}{l}13.44 \\
(2.50)\end{array}$ \\
\hline \multicolumn{3}{|l|}{ Categorical education } \\
\hline No high school & $\begin{array}{c}.20 \\
(.40)\end{array}$ & $\begin{array}{c}.10 \\
(.30)\end{array}$ \\
\hline High school & $\begin{array}{c}.36 \\
(.48)\end{array}$ & $\begin{array}{c}.43 \\
(.50)\end{array}$ \\
\hline Some college & $\begin{array}{c}.21 \\
(.41)\end{array}$ & $\begin{array}{c}.21 \\
(.41)\end{array}$ \\
\hline Four-year college or beyond & $\begin{array}{c}.22 \\
(.41)\end{array}$ & $\begin{array}{c}.26 \\
(.44)\end{array}$ \\
\hline \multicolumn{3}{|l|}{ (b) Ability and family background } \\
\hline Armed forces qualifying test score (adjusted) & $\begin{array}{c}43.30 \\
(29.21)\end{array}$ & $\begin{array}{c}62.35 \\
(28.50)\end{array}$ \\
\hline Highest grade mother & $\begin{array}{l}11.10 \\
(3.20)\end{array}$ & $\begin{array}{l}11.85 \\
(2.61)\end{array}$ \\
\hline Highest grade father & $\begin{array}{l}11.12 \\
(3.93)\end{array}$ & $\begin{array}{l}12.01 \\
(3.53)\end{array}$ \\
\hline Number of siblings & $\begin{array}{c}3.63 \\
(2.52)\end{array}$ & $\begin{array}{c}3.16 \\
(2.17)\end{array}$ \\
\hline Family income & $\begin{array}{l}23,320 * \\
(16,941)\end{array}$ & $\begin{array}{l}50,321 * \\
(34,544)\end{array}$ \\
\hline Black & $\begin{array}{l}.25 \\
(.42)\end{array}$ & $\begin{array}{c}.11 \\
(.31)\end{array}$ \\
\hline Hispanic & $\begin{array}{c}.14 \\
(.35)\end{array}$ & $\begin{array}{c}.05 \\
(.22)\end{array}$ \\
\hline \multicolumn{3}{|l|}{ (c)Geographic controls at age 14} \\
\hline Urban & $\begin{array}{c}.79 \\
(.41)\end{array}$ & $\begin{array}{c}.77 \\
(.42)\end{array}$ \\
\hline Northeast & $\begin{array}{l}.19 \\
(.39)\end{array}$ & $\begin{array}{c}.21 \\
(.41)\end{array}$ \\
\hline South & $\begin{array}{c}.33 \\
(.47)\end{array}$ & $\begin{array}{c}.29 \\
(.45)\end{array}$ \\
\hline West & $\begin{array}{c}.19 \\
(.39)\end{array}$ & $\begin{array}{c}.15 \\
(.36)\end{array}$ \\
\hline \multicolumn{3}{|l|}{ (d) Instrument for schooling } \\
\hline Average unemployment during schooling years & $\begin{array}{l}25.33 \\
(5.62)\end{array}$ & \\
\hline
\end{tabular}

*1999 dollars. Average unemployment rates calculated on CPS data. 
Table 1b. Mean and standard deviation time variant variables NLSY79

\begin{tabular}{lccccc}
\hline & \multicolumn{5}{c}{ Our Sample } \\
\cline { 2 - 6 } Labor market variables & 1990 & 1993 & 1995 & 1997 & 1999 \\
\hline Actual work experience & 10.03 & 12.77 & 14.40 & 16.09 & 17.93 \\
& $(3,58)$ & $(4.05)$ & $(4.35)$ & $(4.68)$ & $(5.04)$ \\
Log Hourly earnings & 2.18 & 2.16 & 2.28 & 2.26 & 2.21 \\
& $(.98)$ & $(1.06)$ & $(1.06)$ & $(1.14)$ & $(1.25)$ \\
Unemployment rate & 5.81 & 8.70 & 6.01 & 5.59 & 4.12 \\
& $(2.13)$ & $(2.51)$ & $(1.74)$ & $(1.87)$ & $(1.05)$ \\
\hline & \multicolumn{7}{c}{ Chen's sample } & & & \\
\cline { 2 - 6 } & 1990 & 1993 & 1995 & 1997 & 1999 \\
\hline Labor market variables & 9.03 & 11.47 & 13.25 & 15.01 & 16.74 \\
Actual work experience & $(3.37)$ & $(3.87)$ & $(4.11)$ & $(4.34)$ & $(4.67)$ \\
Log Hourly earnings* & 2.42 & 2.47 & 2.51 & 2.59 & 2.70 \\
& $(.68)$ & $(.69)$ & $(.70)$ & $(.84)$ & $(.85)$ \\
\hline Note: *in 1992 dollars. Stand year
\end{tabular}

Note: *in 1992 dollars. Standard deviations in parenthesis. Unemployment rates are taken from CPS.

\section{Replication}

We will present our results in three steps: first stage estimates to instrument schooling levels, GLS and IV wage equations, and decomposition of variances of observed wages, potential wages and uncertainty. In each of these tables, columns in bold report the results of our estimates, while the normal print reproduces Chen's original results. We have scrupulously tested our estimation routine through a Monte-Carlo simulation (results available on request). Our routine was able to retrieve all the parameters of the simulated dataset with good precision. Therefore, we exclude that discrepancies reported below are the result of a misunderstanding of the estimation procedure.

\section{A. First Stage: using national unemployment rates as instrument}

Table 2 reports the results of the ordered probit taking schooling level as the explained variable. Given that we have to use a different instrument, it is important to point to the significant effect that our instrument has for every level of education even after controlling for ability, family background, racial and geographical origin and age. Overall our fit is similar to Chen's. All covariates show the same sign and roughly the same magnitude. The only appreciable difference between the two estimations is the magnitude of the two sets of cutoff points. Our cutoff points are negative and the intervals are wider. It's perhaps remarkable that the effect of the unemployment rate is negative. One usually reasons that the opportunity cost of schooling falls when unemployment is high. But of course the benefits from extended schooling may fall even more during a recession, thus making the investment less profitable. 
Table 2. First stage estimates ordered probit and marginal effects.

\begin{tabular}{|c|c|c|c|c|c|c|c|c|c|c|}
\hline \multirow[b]{3}{*}{ Covariates } & \multirow{2}{*}{\multicolumn{2}{|c|}{ Coefficients }} & \multicolumn{8}{|c|}{ Marginal effect at means } \\
\hline & & & \multicolumn{2}{|c|}{ Less than high school } & \multicolumn{2}{|c|}{ High school } & \multicolumn{2}{|c|}{ Some college } & \multicolumn{2}{|c|}{4 year college or beyond } \\
\hline & (1) & (2) & (3) & (4) & (5) & (6) & (7) & (8) & (9) & $(10)$ \\
\hline \multirow[t]{2}{*}{ Tuition cost in county $/ 1,000$} & & $-.055 * * *$ & & $.010^{* * *}$ & & $.012 * * *$ & & $-007 * *$ & & $-.015 * *$ \\
\hline & & $(.012)$ & & $(.002)$ & & $(.003)$ & & $(.002)$ & & $(.003)$ \\
\hline \multirow{2}{*}{$\begin{array}{l}\text { Average unemployment rate during } \\
\text { schooling years }\end{array}$} & $-.063 * * *$ & & $.009 * * *$ & & $.016 * * *$ & & $-.009 * * *$ & & $-.016 * * *$ & \\
\hline & $(.005)$ & & $(.001)$ & & $(.001)$ & & $(.001)$ & & $(.001)$ & \\
\hline \multicolumn{11}{|l|}{ Interact unemp. Rate with/ } \\
\hline \multirow[t]{2}{*}{ Mother attended college } & $.071^{* * *}$ & & $-.010 * * *$ & & $-.018 * * *$ & & $.010^{* * *}$ & & $.018^{* * *}$ & \\
\hline & $(.009)$ & & $(.001)$ & & $(.002)$ & & $(.001)$ & & $(.002)$ & \\
\hline \multirow[t]{2}{*}{ Father attended college } & $.055^{* * *}$ & & $-.008 * * *$ & & $-.014 * * *$ & & $.007 * * *$ & & $.014 * * *$ & \\
\hline & $(.008)$ & & $(.001)$ & & $(.002)$ & & $(.001)$ & & (.002) & \\
\hline \multirow[t]{2}{*}{ Highest grade mother } & $.040^{* * *}$ & $.033 * *$ & $-.006 * * *$ & $-.006 * *$ & $-.010 * * *$ & $-.007^{*}$ & $.005^{* * *}$ & $.004 *$ & $.010 * * *$ & $.009 * *$ \\
\hline & $(.005)$ & $(.011)$ & $(.001)$ & $(.002)$ & $(.001)$ & $(.003)$ & (.001) & $(.002)$ & $(.001)$ & $(.003)$ \\
\hline \multirow[t]{2}{*}{ Highest grade father } & $.048 * * *$ & $.029 * *$ & $-.007 * * *$ & $-.005^{*}$ & $-.012 * * *$ & $-.006^{* *}$ & $.007 * * *$ & $.004 * * *$ & $.013^{* * *}$ & $.008^{* * *}$ \\
\hline & $(.004)$ & $(.009)$ & $(.001)$ & $(.002)$ & $(.001)$ & $(.002)$ & $(.001)$ & $(.001)$ & $(.001)$ & $(.002)$ \\
\hline \multirow[t]{2}{*}{ Family income bottom quartile } & .010 & -.199 & .002 & .039 & .003 & .038 & -.002 & -.029 & -.003 & -.049 \\
\hline & $(.035)$ & $(.154)$ & $(.005)$ & $(.033)$ & (.009) & $(.025)$ & $(.005)$ & $(.024)$ & $(.009)$ & $(.34)$ \\
\hline \multirow[t]{2}{*}{ Family income second quartile } & -.058 & -.005 & $.009 *$ & .001 & $.016^{*}$ & .001 & $-.009 *$ & -.001 & $-.016 *$ & -.001 \\
\hline & $(.031)$ & $(.153)$ & $(.005)$ & $(.027)$ & (.008) & $(.033)$ & $(.005)$ & $(.020)$ & $(.008)$ & $(.040)$ \\
\hline \multirow[t]{2}{*}{ Family income third quartile } & .014 & .061 & -.004 & -.010 & -.007 & -.014 & .004 & .009 & .007 & .016 \\
\hline & $(.028)$ & $(.15)$ & $(.004)$ & $(.025)$ & $(.007)$ & $(.035)$ & $(.004)$ & $(.018)$ & $(.007)$ & $(.041)$ \\
\hline \multirow[t]{2}{*}{ Family income top quartile } & $.238^{* * *}$ & .164 & $-.033^{* * *}$ & -.027 & $-.065 * * *$ & -.038 & $.031 * * *$ & .020 & $.067^{* * *}$ & .045 \\
\hline & $(.028)$ & $(.151)$ & $(.004)$ & $(.023)$ & $(.008)$ & $(.037)$ & $(.003)$ & $(.016)$ & $(.008)$ & (.044) \\
\hline \multirow[t]{2}{*}{ AFQT score (adjusted) } & $.028 * * *$ & $.024 * * *$ & $-.004 * * *$ & $-.004 * * *$ & $-.007 * * *$ & $-.005^{* * *}$ & $.004 * * *$ & $.003^{* * *}$ & $.007 * * *$ & $.006^{* * *}$ \\
\hline & $(.000)$ & $(.001)$ & $(.000)$ & $(.0002)$ & $(.000)$ & $(.0003)$ & $(.000)$ & $(.0002)$ & $(.000)$ & $(.0003)$ \\
\hline \multirow[t]{2}{*}{ Black } & $.713^{* * *}$ & $.653^{* * *}$ & $-.069 * * *$ & $-.082 * * *$ & $-.206 * * *$ & $-.173^{* * *}$ & $.045^{* * *}$ & $.047^{* * *}$ & $.230^{* * *}$ & $.208^{* * *}$ \\
\hline & $(.026)$ & $(.056)$ & $(.002)$ & $(.006)$ & $(.008)$ & $(.017)$ & $(.002)$ & $(.004)$ & (.009) & $(.020)$ \\
\hline \multirow[t]{2}{*}{ Hispanic } & $.587 * * *$ & $.435^{* * *}$ & $-.057 * * *$ & $-.059 * * *$ & $-.171^{* * *}$ & $-.113^{* * *}$ & $.039^{* * *}$ & $.038^{* * *}$ & $.189 * * *$ & $.134 * * *$ \\
\hline & $(.037)$ & $(.070)$ & $(.003)$ & $(.008)$ & $(.011)$ & $(.020)$ & $(.002)$ & $(.004)$ & $(.013)$ & $(.024)$ \\
\hline Geographic controls & Yes & Yes & Yes & Yes & Yes & Yes & Yes & Yes & Yes & Yes \\
\hline Cohort and age controls & Yes & Yes & Yes & Yes & Yes & Yes & Yes & Yes & Yes & Yes \\
\hline \multirow[t]{2}{*}{ Constant(K0) } & $-11.955^{* * *}$ & $.711^{*}$ & & & & & & & & \\
\hline & $(.254)$ & $(.315)$ & & & & & & & & \\
\hline Cut point (K1) & $-9.793^{* * *}$ & $2.148^{* * *}$ & & & & & & & & \\
\hline & $(.241)$ & $(0.316)$ & & & & & & & & \\
\hline Cut point(K2) & $-8.352^{* * *}$ & $2.905 * * *$ & & & & & & & & \\
\hline & $(.229)$ & $(.317)$ & & & & & & & & \\
\hline Wald chi-squared & $9,064.92$ & $1,148.6$ & & & & & & & & \\
\hline
\end{tabular}




\section{B. Causal effects of schooling on average wages}

The estimates of the causal effects of schooling on wages are presented in table 3. Our GLS estimation shows the expected positive effect of education, experience and ability on wages. In our case, returns to education increase while in Chen's case both high school graduates and college graduates have higher benefits from schooling after instrumenting. In our case, Hispanics also appear to earn more after instrumenting. In stark contrast to Chen's results, we find no significant effect of the selectivity correction terms. The different effects of the four inverse Mill's ratios will have a strong impact on the calculations of the correlation coefficient $\rho_{s}$ and, in turn, on the estimate of potential wage inequality $\sigma_{s}^{2}$. 
Table 3. Wage equations: estimates of GLS and Heckman selection model

\begin{tabular}{|c|c|c|c|c|}
\hline \multirow[b]{2}{*}{ Covariates } & \multicolumn{2}{|c|}{$\begin{array}{l}\text { Between-individual } \\
\text { model(GLS) }\end{array}$} & \multicolumn{2}{|c|}{ Heckman } \\
\hline & (1) & $(2)$ & (3) & $(4)$ \\
\hline \multirow[t]{2}{*}{ High school graduates } & $.085^{* * *}$ & $.088 * *$ & .036 & $.371 * *$ \\
\hline & $(.012)$ & $(.030)$ & (.039) & $(.148)$ \\
\hline \multirow[t]{2}{*}{ Some college } & $.132 * * *$ & $.242 * * *$ & $.106 *$ & $.242 * * *$ \\
\hline & $(.014)$ & $(.081)$ & $(.045)$ & $(.081)$ \\
\hline \multirow[t]{2}{*}{ Four-year college or beyond } & $.397 * * *$ & $.241 * * *$ & $.428 * * *$ & $.599 * * *$ \\
\hline & $(.016)$ & $(.028)$ & $(.057)$ & $(.116)$ \\
\hline \multirow[t]{2}{*}{ Experience } & $.130 * * *$ & $.076 * * *$ & $.184 * * *$ & $.074 * * *$ \\
\hline & $(.005)$ & $(.014)$ & (.011) & $(.014)$ \\
\hline \multirow[t]{2}{*}{ Experience2 } & $-.001 * * *$ & -.001 & $-.004 * * *$ & -.001 \\
\hline & $(.000)$ & $(.001)$ & $(.000)$ & $(.001)$ \\
\hline \multirow[t]{2}{*}{ AFQT score (adjusted) } & $.005 * * *$ & $.004 * * *$ & $.004 * * *$ & .0005 \\
\hline & $(.000)$ & $(.000)$ & $(.001)$ & $(.002)$ \\
\hline \multirow[t]{2}{*}{ Mother's years of schooling } & -.003 & $.008 *$ & -.003 & -.005 \\
\hline & $(.002)$ & $(.004)$ & (.004) & $(.005)$ \\
\hline \multirow[t]{2}{*}{ Father's years of schooling } & -.000 & .003 & .003 & -.004 \\
\hline & $(.001)$ & $(.003)$ & (.003) & $(.004)$ \\
\hline \multirow[t]{2}{*}{ Family income bottom quartile } & $.005 * *$ & -.005 & .027 & .015 \\
\hline & $(.002)$ & $(.056)$ & (.035) & $(.057)$ \\
\hline \multirow[t]{2}{*}{ Family income second quartile } & .001 & .037 & -.024 & .025 \\
\hline & $(.015)$ & $(.055)$ & $(.032)$ & $(.055)$ \\
\hline \multirow[t]{2}{*}{ Family income third quartile } & $-.030 *$ & .059 & .018 & .038 \\
\hline & $(.013)$ & $(.054)$ & (.030) & $(.055)$ \\
\hline \multirow[t]{2}{*}{ Family income top quartile } & -.002 & .093 & $.085 * *$ & .053 \\
\hline & $(.012)$ & $(.054)$ & $(.030)$ & $(.057)$ \\
\hline \multirow[t]{2}{*}{ Number of siblings } & $.005 * *$ & -.0004 & .000 & .003 \\
\hline & $(.002)$ & $(.004)$ & $(.004)$ & $(.004)$ \\
\hline \multirow[t]{2}{*}{ Black } & $.064 * * *$ & $-.053 * *$ & $.331 * *$ & $-.158 * * *$ \\
\hline & $(.013)$ & $(.026)$ & (.128) & $(.053)$ \\
\hline \multirow[t]{2}{*}{ Hispanic } & $.039 *$ & .020 & $.255^{* *}$ & -.062 \\
\hline & (.015) & $(.029)$ & $(.087)$ & $(.045)$ \\
\hline \multirow[t]{2}{*}{ Unemployment rate } & -.001 & & $-.072 * *$ & \\
\hline & $(.002)$ & & $(.026)$ & \\
\hline \multirow[t]{2}{*}{ Constant } & $.329 * * *$ & $1.118 * * *$ & $.892 * * *$ & $1.077 * * *$ \\
\hline & $(.046)$ & $(.103)$ & $(.172)$ & $(.117)$ \\
\hline Geographic controls & Yes & Yes & Yes & Yes \\
\hline Cohort and age controls & Yes & Yes & Yes & Yes \\
\hline \multicolumn{5}{|l|}{ Selectivity adjustments } \\
\hline \multirow[t]{2}{*}{ No High school } & & & .028 & $-.303 * *$ \\
\hline & & & (.025) & $(.113)$ \\
\hline \multirow[t]{2}{*}{ High school graduates } & & & -.042 & $-.182 * *$ \\
\hline & & & (.028) & $(.089)$ \\
\hline Some college & & & -.030 & -.099 \\
\hline & & & (.022) & $(.079)$ \\
\hline Four-year college or more & & & -.066 & $-.324 * * *$ \\
\hline & & & $(.047)$ & $(.106)$ \\
\hline R-squared & .404 & .311 & .450 & .320 \\
\hline
\end{tabular}




\section{Main results}

In table $4 \mathrm{a}$ panel $\mathrm{A}$ we report observed wage inequality and its two components. The first is the permanent component, identified by the mean squared residuals in the between-individuals model $^{15}$ (equation 10). The second is the transitory component $\psi_{s t}^{2}$ identified by exploiting the mean-squared errors of the fixed-effects model as described in note 9 p. 278 in Chen $(2008)^{16}$. Transitory volatility $\psi_{s t}^{2}$ is consistently estimated by ${ }^{17}$ :

$$
\hat{\psi}_{s t}^{2}=\hat{V}_{s t} N^{-1} \sum_{i} T_{i} /\left(T_{i}-2\right)-N^{-1} \sum_{i} \hat{\Omega}_{s i} /\left(T_{i}\left(T_{i}-2\right)\right),
$$

where $\hat{V}_{s t}$ is the mean squared errors of the fixed-effects model and $\hat{\Omega}_{s}=\sum \hat{V}_{s t} /\left(1-1 / T_{i}\right)$.

Our estimates of the permanent component are larger than Chen's but the ranking is the same and even the differences between schooling levels are very close. Our estimates of the transitory component are smaller than Chen's; our profile across levels of schooling is fairly flat, whereas in Chen's case, there is a substantial dip after high school drop-outs and stability thereafter. The results for total observed inequality also differ. In Chen's results, the group with some college stands out with low variance, while in our results, college graduates stand out with the highest variance. Remarkably, in both estimates the oldest age group has the highest transitory variance.

\footnotetext{
${ }^{15}$ Chen affirms on page 283 that the permanent component is defined as the variance in the individual fixed effect model. This would conflict with the definition given on page 278 and with equation 12. For this reason, we will adhere to the definition provided on page 278 and use the mean squared errors of the between-individuals model.

${ }^{16}$ In a footnote to table 4 Chen (2008 p. 284) affirms that: "The estimates of transitory volatility are derived by regressing squared residuals on age dummies and categorical education variables". This seems to contrast with the specification of the transitory volatility parameter $\psi_{s t}^{2}$ provided in note 9 p.278 that we adopted for our estimates. We have estimated the transitory parameter also with this alternative specification and results are very similar. Estimates available on request.

${ }^{17}$ As mentioned in footnote 2, Chen does not add a time subscript to the parameter $\tau_{s}^{2}$ and when she presents the parameter estimate, she does not make it dependent on time either but only reports differences by age group (possibly for brevity of exposition). While we do have separate estimates of this parameter for each year, we will follow Chen's methodology and distinguish only within age groups. Measurement of the transitory component is not clear. The note to Chen's table 4 states that: "the estimates of transitory volatility are derived by regressing squared residuals on age dummies and categorical education variables." (Chen, 2008 p. 284). This procedure seems to contrast with the one highlighted in note 9 p.278. The squared residuals mentioned in Chen's note are most likely those obtained from the fixed-effect model. Since we could not understand whether the outcome variable she regresses the categorical education and age dummies on is the variance of residuals of the fixed effect model or $\hat{\psi}_{s t}^{2}$ we have applied both methods. The differences are negligible.
} 
This results contradicts past results (Chen, 2008) that pointed towards a decrease in wage variance with age.

As shown in Panel A, for every educational category, we systematically obtain a larger permanent component than Chen. The difference varies between $32 \%$ for high school drop outs and $25 \%$ for college dropouts. Remember that the permanent component here is defined simply as the mean squared residuals of the GLS model presented in table $3 \mathrm{~b}$ columns 1 and 2 . This means that our residual should be larger than Chen's. This is contradicted by our R-squared which is substantially higher than the one in Chen (2008).

Table 4a. Estimates of variance of observed wage inequality.

\begin{tabular}{|c|c|c|c|c|c|c|c|c|}
\hline & \multicolumn{2}{|c|}{$\begin{array}{l}\text { Less than high } \\
\text { school }\end{array}$} & \multicolumn{2}{|c|}{ High school } & \multicolumn{2}{|c|}{ Some college } & \multicolumn{2}{|c|}{$\begin{array}{l}\text { College } \\
\text { graduates }\end{array}$} \\
\hline & (1) & $(2)$ & (3) & $(4)$ & (5) & (6) & (7) & $(8)$ \\
\hline \multirow[t]{2}{*}{ A. Permanent component } & .322 & .218 & .306 & .214 & .357 & .267 & .420 & .292 \\
\hline & (.019) & $(0.26)$ & (.016) & $(0.14)$ & (.023) & $(0.28)$ & $(.026)$ & $(.022)$ \\
\hline B. $\left(\hat{\psi}_{s t}^{2}\right)$-Transitory component & .149 & .293 & .131 & .197 & .142 & .233 & .206 & .221 \\
\hline Age $25-30$ & -.056 & .242 & -.051 & .143 & -.043 & .177 & -.104 & .166 \\
\hline Age $31-36$ & -.054 & .320 & -.054 & .221 & -.046 & .254 & -.109 & .244 \\
\hline Age $37-42$ & -.024 & .331 & -.023 & .232 & -.020 & .266 & -.055 & .255 \\
\hline Observed inequality $(\mathrm{A}+\mathrm{B})$ & .471 & .511 & .437 & .411 & .499 & .500 & .626 & .513 \\
\hline \multicolumn{9}{|l|}{ C. $\left(\sigma_{s}^{2}\right)$-Permanent component } \\
\hline $\begin{array}{l}\text {-Adjusted for selection and truncation } \\
\text { biases }\end{array}$ & .223 & .284 & .223 & .242 & .256 & .274 & .312 & .356 \\
\hline \multicolumn{9}{|l|}{ E. Transitory component (same as B) } \\
\hline Potential wage inequality $(\mathrm{C}+\mathrm{E})$ & .372 & .577 & .354 & .439 & .398 & .507 & .518 & .577 \\
\hline F. Correlation coefficient & .058 & -.568 & -.092 & -.371 & -.062 & -.190 & -.124 & -.534 \\
\hline $\begin{array}{l}\text { G. Permanent component }(\mathrm{C}-\mathrm{C} * \mathrm{~F} 2) \\
\text {-Accounted for unobserved } \\
\text { Schooling Factor }\end{array}$ & .222 & .192 & .222 & .209 & .255 & .264 & .307 & .251 \\
\hline \multicolumn{9}{|l|}{ I. Transitory component (same as B) } \\
\hline Degree of wage uncertainty $(\mathrm{G}+\mathrm{I})$ & .371 & .293 & .353 & .197 & .397 & .233 & .513 & .221 \\
\hline $\begin{array}{l}\gamma \text {-Unobserved heterogeneity }(\mathrm{C}+\mathrm{E}- \\
\mathrm{G}-\mathrm{I})\end{array}$ & .001 & .092 & .001 & .033 & .001 & .010 & .005 & .105 \\
\hline
\end{tabular}

In Table $4 \mathrm{~b}$ we present estimates of potential wage inequality, the sum of the permanent component after taking out the effects of selection and truncation and the transitory component $\left(\sigma_{s}^{2}+\psi_{s t}^{2}\right)$. Chen has analytically shown how observed wage inequality systematically understates potential inequality if education were randomly 
assigned (Chen, 2008, p 278). She corrects this by incorporating a truncation adjustment term and a heterogeneity term (equation (11) above). Comparing row A in table $4 \mathrm{a}$ with row $\mathrm{C}$ in table $4 \mathrm{~b}$, shows that the prediction is not confirmed in our data: potential inequality is smaller than observed inequality. The result would suggest that pupils select themselves into the wrong educational category or that their schooling factor does not influence their choice. Since these results are quite surprising we conducted some robustness checks with Monte-Carlo simulation. We tried different instruments such as number of siblings and being raised in a Jewish family, but both elaborations led to the same surprising result.

The result is theoretically impossible if normality in the error terms is assumed, but there are no restrictions in Chen's estimation method impeding it. The permanent component $\sigma_{s}^{2}$ is defined in equation (14). The first term of the sum is the observed wage inequality presented in row $\mathrm{A}$ and it enters also in the calculation of the potential wage inequality in row $\mathrm{C}$. The difference between the two rows is due to the two remaining terms in (14). The only restriction on these two terms regards the truncation adjustment $\left(\delta_{s i}\right)$ : it should range between 0 and 1 . This restriction is respected in our estimation. If the second term of the addition $\left(\widehat{\gamma}_{s}^{2} \overline{\widehat{\delta}}_{s}\right)$ dominates the third term $\left(\sum_{t} \widehat{\psi}_{s t}^{2} / \bar{T}\right)$, potential wage inequality is higher than observed wage inequality. In our case the third term dominates the second and thus the unexpected result emerges. The low value of the second term is related to the low value of the correlation coefficient, as reported in Table 4c: the correlation coefficient determines the magnitude of the correction for selectivity, and in our case, this correction is very small. Conceivably, the result is due to inability of our instrument to create an adequate correction to the biased GLS estimator. But our instrument is surely relevant, as shown in the first stages reported. Since we have a just identified model, we cannot test its validity with a Sargan test, but we have no reason to believe that the country unemployment rate in youth years would have any effect on this group of respondent's wages once we control for current unemployment rates. Furthermore, our instrument performs well in the IV estimation presented in table 3.

Our results and Chen's both point to a permanent component in potential wage inequality that is more or less stable across the lowest three education levels and then jumps for college graduates. But the outcomes differ for total potential inequality: in 
our case it is markedly higher for college graduates than for the other education levels, whereas in Chen's case the pattern is U-shaped and inequality for college graduates is not higher than for high school drop-outs.

The key result of the analysis is the breakdown of observed wage inequality into uncertainty (pure risk) and heterogeneity (table 4c). We find dramatically lower correlation between the unobserved schooling factor and the unobserved permanent component in wages. By consequence, accounting for unobserved schooling factors, as done in row $\mathrm{H}$, has minimal effect on the estimated magnitude of the permanent component of wage inequality. Only for college graduates we see a minor reduction of about $5 \%$. Chen's core conclusion survives: unobserved heterogeneity is negligible; wage inequality is completely dominated by uncertainty. But in our estimates, uncertainty is clearly highest for college graduates, while in Chen's estimates it is highest for high school graduates.

\section{Conclusion on the replication}

We have been unable to replicate Chen (2008) exactly. Data availability regulations prevented us from using the same instrument. Chen's instrument for schooling, local tuition cost, may be particularly relevant for students from poor families and with relatively low ability. Number of siblings, our instrument in the British and German case, may have similar relevance. Our instrument for the US data, the national unemployment rate, has a negative effect on the inclination to continue into higher education. This is compatible with standard human capital theory if benefits from extended education decline more than the cost of education with rising unemployment, a case that may well hold for low ability students from poor families. Chen's description of her procedures was not always unequivocal. Following the instructions in Chen's original paper did not bring us to the same sample of individuals. In our sample, we have a larger share of lower educated individuals, from poorer family backgrounds. This may lead to difference in estimated coefficients. If less advantaged people are more prone to lose their job we would observe a higher transitory volatility. In reality what we observe is a lower transitory volatility in our replication. Less advantaged individuals might also posses less private information or they might not be able to use it correctly and that would reflect in higher share of pure risk and possibly in higher observed than potential permanent variance. In effect that 
is what we observe in our elaboration. The sensitivity of our results to modest changes in sample composition is reason for concern. We do feel confident though, that our estimation procedure faithfully reflects Chen's model.

In our estimates, the transitory component in observed wage inequality is about $1 / 2$ to $1 / 3$ of the permanent component, while in Chen's estimates they are about equal. Chen finds that potential wage inequality is larger than observed inequality, while we find the reverse (at a larger gap). In our case, observed wage inequality is virtually identical to uncertainty, leaving no room for unobserved heterogeneity, and this conclusion is similar to what Chen finds (her heterogeneity is marginally bigger). We find that uncertainty is close to $40 \%$ higher for college graduates than for high school drop-outs, while Chen finds that high school drop-outs have some $30 \%$ higher uncertainty than college graduates.

\section{Applying the analysis to American women}

We extend the analysis to women in the NLSY sample, but to avoid complications due to labor market participation behavior, we restrict the analysis to full time female workers only. We define full time workers as those women who worked at least 25 hours per week in each survey year. Applying the same selection criteria adopted in the previous section we obtain a sample with 2535 observations. The full time working women are more educated, by almost one year, than the male sample. They are also more able as measured by the AFQT adjusted test score. This is not surprising given the particular condition we imposed. It is indeed probable that highly educated women are more likely to participate in the labor market (Connelly, 1992) and thus be included in our analysis. As for the time variant variables, full time working women show a better performance in the labor market. They have a substantially higher working experience and earn more than their male counterparts.

The first stage estimates are not shown here. No appreciable difference emerges between the previous first stages based on men only and these new ones. The instrument is still relevant and has the same impact on further education. The cut-off points are modified. The interval between the three points is slightly larger than before. 
Also, the between-individuals model, instrumental variable estimation and Heckman second stage do not present appreciable differences between the female and male samples. Full time working females belonging to ethnical minorities earn more than their white counterparts. This is probably reflecting that ethnic minority females that decide or succeed to work full time are particularly talented or dedicated. The other covariates do not show significant differences with the estimates presented earlier for men only.

Table 6a. Estimates of variance of observed wage inequality - Full time females workers.

\begin{tabular}{|c|c|c|c|c|c|c|c|c|}
\hline & \multicolumn{2}{|c|}{$\begin{array}{l}\text { Less than high } \\
\text { school }\end{array}$} & \multicolumn{2}{|c|}{ High school } & \multicolumn{2}{|c|}{ Some college } & \multicolumn{2}{|c|}{ College } \\
\hline & $\mathrm{F}$ & $\mathrm{M}$ & $\mathrm{F}$ & M & $\mathrm{F}$ & M & $\mathrm{F}$ & $\mathrm{M}$ \\
\hline A. Permanent component & $\begin{array}{c}.074 \\
(.007)\end{array}$ & $\begin{array}{l}.322 \\
(.019)\end{array}$ & $\begin{array}{l}.115 \\
(.005)\end{array}$ & $\begin{array}{c}.306 \\
(.016)\end{array}$ & $\begin{array}{l}.118 \\
(.007)\end{array}$ & $\begin{array}{l}.357 \\
(.023)\end{array}$ & $\begin{array}{l}.190 \\
(.009)\end{array}$ & $\begin{array}{l}.420 \\
(.026)\end{array}$ \\
\hline B. Transitory component $\left(\hat{\psi}_{s t}^{2}\right)$ & .009 & .149 & .026 & .131 & .033 & .142 & .032 & .206 \\
\hline Age $25-30$ & .007 & -.056 & -.004 & -.051 & -.005 & -.043 & .003 & -.104 \\
\hline Age $31-36$ & .005 & -.054 & -.004 & -.054 & -.010 & -.046 & -.002 & -.109 \\
\hline Age $37-42$ & .001 & -.024 & -.001 & -.023 & -.003 & -.020 & -.003 & -.055 \\
\hline Observed inequality $(\mathrm{A}+\mathrm{B}$ ') & .083 & .471 & .141 & .437 & .151 & .499 & .222 & .626 \\
\hline $\begin{array}{l}\text { C. }\left(\sigma_{s}^{2}\right) \text {-Permanent component } \\
\text {-Adjusted for selection and truncation } \\
\text { biases } \\
\text { E. Transitory component (same as B) }\end{array}$ & .062 & .223 & .093 & .223 & .092 & .256 & .159 & .312 \\
\hline Potential wage inequality $(\mathrm{C}+\mathrm{E})$ & .071 & .372 & .119 & .354 & .125 & .398 & .191 & .518 \\
\hline $\begin{array}{l}\text { F. Correlation coefficient } \\
\text { G. Permanent component (C-C*F2) }\end{array}$ & .204 & .058 & -.061 & -.092 & .023 & -.062 & .076 & -.124 \\
\hline $\begin{array}{l}\text {-Accounted for unobs. Schooling } \\
\text { Factor } \\
\text { I. Transitory component (same as B) }\end{array}$ & .059 & .222 & .093 & .222 & .092 & .255 & .158 & .307 \\
\hline Degree of wage uncertainty $(\mathrm{G}+\mathrm{I})$ & .024 & .371 & .119 & .353 & .125 & .397 & .190 & .513 \\
\hline $\begin{array}{l}\gamma \text {-Unobserved heterogeneity }(\mathrm{C}+\mathrm{E}- \\
\mathrm{G}-\mathrm{I})\end{array}$ & .003 & .001 & .000 & .001 & .000 & .001 & .001 & .005 \\
\hline
\end{tabular}

As the results in table 6 show, essentially all inequality measures are smaller for women than for men, in most cases quite substantially so. The women that we now included are working full time over the entire period of analysis and therefore, by construction, the variability of their wages must be lower than those of males who are allowed to experience unemployment spells - with the consequent sudden fall of income - and still be part of the sample. This is also reflected in the very low values of transitory volatility. As for men, potential wage inequality is lower than observed 
wage inequality. Both observed and potential wage inequality are increasing with education level, just as for men. The correlation coefficients shown in table 6c are bigger than before, but still much smaller than those calculated by Chen and truncation and selection adjustment have minimal impact on permanent components. The most affected category is college drop out whose permanent component has a $28 \%$ decrease.

Potential wage inequality is completely dominated by uncertainty, even stronger than for men; unobserved heterogeneity is virtually absent. Uncertainty, just as for men in our estimates, is increasing in level of education.

\section{Estimation on British data}

The British Household Panel Survey (BHPS) is an annually collected survey that begun in 1991. Every year a representative sample of 5,500 households, containing approximately 10,000 individuals, is interviewed. If a member of the original sample splits-off from his original family, he is followed in the new household and all adults members of the new family are interviewed as well. Also new members joining a selected family are added to the sample and children are interviewed once they reach age 16. Further extensions to Welsh, Scottish and Northern Irish families increased the sample size to 10,000 households across the UK. We could access the surveys until 2008; therefore 18 waves are included in our analysis.

As the required unemployment data are not available to us, we used number of siblings in the family as instrument for schooling. An additional brother/sister will limit the share of family income dedicated to a particular child's education. Families might decide to pay only for the education of those children who show a better inclination for studies. Then, number of siblings will be negatively correlated with schooling years and probability to access higher educational levels. We reconstruct the number of siblings for those young individuals who were still living with their parents in the first year of the survey. Our sample is limited to those individuals that were classified as sons in the first wave (we focused on men for the usual reason). Our sample is, for this reason, reduced to 16,359 individuals. From the original sample, 7,795 females were deleted. Additionally, we had to drop 1,674 individuals that have 
no information on income and 12,223 observations lacking information on work experience. Our final sample counts 21,403 time-individuals combinations.

The BHPS does not provide any measure comparable to the AFQT score collected in the NLSY nor any other proxy plausibly related to ability. An additional difference between BHPS and NLSY is how earnings are recorded: monthly instead of hourly earnings. This will change the scale of transitory and permanent components that will be presented later on.

\section{A. British educational system}

Compulsory education in the UK lasts for 11 years, from age five until age sixteen. It is divided in four key stages. The first two years (age five to seven) compose the first stage; the following four years (from seven to ten) the second and along with the first stage it constitutes primary education. The third ( 3 years from eleven to thirteen) and fourth ( 2 years from fourteen to fifteen) key stages form, altogether, the secondary education. At the end of secondary education the GSCE (General Certificate for Secondary Education) is awarded in specific subjects. Often, a good score in the GSCE is a requirement for access to further education.

A-levels (Advanced Level of General Education) are the first degree of noncompulsory education and are a prerequisite for access to academic courses in UK institutions. They take two years for completion, from age 16 to age 17 .

University education is divided in two cycles. The first awards a Bachelor degree and generally lasts three years, while the second leads to a Master degree and takes in most cases one year. Along with the standard tertiary education, a number of other professional higher educations such as the Post Graduate Certificate in Education (PGCE) or the Bachelor of Education (BEd) or nursing degrees exist.

\section{B. Wage variance in British data}

In table 7 we only present a summary of the results ${ }^{18}$. Education is divided in six categories: no qualification, vocational secondary education, high school education, A-level qualification, vocational tertiary education and college education or above. Secondary vocational education is a residual category where we placed all respondents who declared to have accomplished secondary education, but have not

\footnotetext{
${ }^{18}$ Descriptive statistics along with estimates of first-stage and wage regressions are available from the authors.
} 
been awarded a GSCE. The group is heterogeneous and includes workers in different sectors. In the tertiary vocational education group we include individuals with PGCE, BEd and nursing degrees. The other four groups are of easy interpretation.

Observed variance is smaller than potential inequality in 3 out of 6 educational categories and larger in the other 3 . The transitory component of inequality is small relative to the permanent component. Correlations differ strongly between education categories and are certainly not low, except for those without any educational qualification. Uncertainty is mostly substantially larger than heterogeneity, except for vocational high school graduates. Observed and potential inequality generally decline with increasing levels of education and so does uncertainty; vocational high school stands out as an exceptional category, with large (negative) correlation, low inequality and high uncertainty.

Table 7. Estimates of variance of wage uncertainty - BHPS data.

\begin{tabular}{|c|c|c|c|c|c|c|}
\hline & $\begin{array}{c}\text { No } \\
\text { qualification }\end{array}$ & $\begin{array}{l}\text { Vocational } \\
\text { high school }\end{array}$ & $\begin{array}{c}\text { High } \\
\text { school }\end{array}$ & A levels & $\begin{array}{c}\text { Higher } \\
\text { vocational }\end{array}$ & $\begin{array}{c}\text { College and } \\
\text { beyond }\end{array}$ \\
\hline \multicolumn{7}{|l|}{ Observed wage inequality } \\
\hline A. Permanent component & 3.395 & .563 & 2.206 & 1.905 & 1.612 & 1.029 \\
\hline B. Transitory component & .245 & .024 & .164 & .159 & .148 & .197 \\
\hline Age $18-25$ & .014 & .121 & .020 & .055 & -.033 & .017 \\
\hline Age 26-35 & .011 & -.004 & -.001 & -.002 & -.034 & -.049 \\
\hline Age $36-45$ & .038 & .122 & -.007 & .007 & -.057 & -.068 \\
\hline Age $46-55$ & .023 & .056 & .014 & -.005 & -.047 & -.072 \\
\hline Age $56-65$ & .047 & .113 & .023 & -.004 & -.057 & -.067 \\
\hline Observed inequality $(\mathrm{A}+\mathrm{B})$ & 3.640 & .587 & 2.370 & 2.064 & 1.760 & 1.226 \\
\hline \multicolumn{7}{|l|}{ Potential wage inequality } \\
\hline C. $\left(\sigma_{s}^{2}\right)$-Permanent component & 3.204 & 1.250 & 2.105 & 1.984 & 1.779 & .990 \\
\hline Potential wage inequality $(\mathrm{C}+\mathrm{B})$ & 3.449 & 1.274 & 2.269 & 2.143 & 1.927 & 1.187 \\
\hline \multicolumn{7}{|l|}{ Wage uncertainty } \\
\hline D. Correlation coefficient & .047 & -.798 & -.144 & .386 & .424 & .412 \\
\hline $\begin{array}{l}\text { E. Permanent component }(C-C * D 2) \\
\text {-Accounted for unobserved } \\
\text { schooling factor }\end{array}$ & 3.197 & .454 & 2.061 & 1.689 & 1.459 & .822 \\
\hline Degree of wage uncertainty $(E+B)$ & 3.658 & .478 & 2.225 & 1.848 & 1.607 & 1.019 \\
\hline$\gamma$-Unobserved heterogeneity $(\mathrm{C}-\mathrm{E})$ & .007 & .796 & .044 & .295 & .320 & .168 \\
\hline
\end{tabular}


The vocational high school group is truly exceptional: observed inequality is about $1 / 6$ of that of the unqualified group. The relatively low variance among vocational high school graduates is caused both by the permanent and transitory component of observed wage inequality. In fact, both parameters are the lowest among the six categories. It is also the category with the highest unobserved heterogeneity.

Accounting for unobserved schooling factor via the introduction of the sibling instrument (panel E) has a noticeable impact for four out of six categories. That is particularly true for vocational high school graduates for whom the $36 \%$ of the truncation adjustment is due to the inclusion of our instrument.

\section{Estimation on German data}

For Germany we used data on males in the Socio-Economic Panel (SOEP), 19842008. There is no proxy for ability and we cannot control for parental family income. Schooling is instrumented by number of siblings. We find a striking difference between observed and potential wage inequality: observed inequality is only a tenth of the potential for every educational level. This is due to a correlation coefficient between wages and the unobserved schooling factor slightly over or slightly under 1 . Technically, it is the result of some huge negative inverse Mill's ratios obtained in the Heckman two-step procedure. The disproportionate correlation coefficient causes other meaningless results such as a negative permanent component accounted for unobserved schooling factor in panel $\mathrm{E}$ or and negative wage uncertainty. For these German data, the Chen model clearly does not apply.

\section{Conclusion}

Variation in observed wages at given levels of education has often been taken as an indication of the risk associated with investing in education (Bonin et al 2007; Diaz Serrano, 2007; Hartog, 2011). Yet, at least conceptually, part of the variation will result from heterogeneity among students and may be foreseen by the potential student when deciding on schooling. In a survey paper of several contributions by Heckman and co-authors, Cunha and Heckman (2007, p.892) conclude: "For a variety of market environments and assumptions about preferences, a robust empirical 
regularity is that over $50 \%$ of the ex post variance in the returns to schooling are foreseeable at the time students make their college choices". Heckman and his associates use elaborate models based on the assumption that if information that only becomes available after schooling has been completed has an impact on schooling choices, it must have been known by the student when deciding on schooling. Their estimation combines different datasets and uses observations on test scores. Chen (2008) distinguishes observed and potential inequality and decomposes potential wage inequality into uncertainty and unobservable heterogeneity, by allowing for selfselection and truncation biases along more traditional Heckman lines. .

We take six main conclusions from Chen's original paper. First, potential wage inequality is larger than observed wage inequality. Second, the transitory component in observed inequality is about equal to permanent inequality. Third, observed and potential inequality are both more or less stable across level of education. Fourth, the correlations between the unobserved schooling factor and the permanent individual effect in wages are negative and not negligible Fifth, the most essential conclusion for our present purpose: unobserved heterogeneity is negligible compared to uncertainty as it only accounts for $1.1 \%$ of potential wage variability for college graduates and $0.3 \%$ for the other three groups. Sixth, uncertainty is highest for high school drop-outs and about constant for the other three schooling levels.

In our replication on the same dataset we are unable to confirm these results. We find that potential inequality is smaller, instead of larger that observed inequality. The transitory component in observed inequality is not equal to the permanent component but only $1 / 3$ to $1 / 2$ of it. Observed and potential inequalities are only constant for high school graduates and beyond: high school drop-outs have higher values. The correlation coefficients we obtain are also negative but very small. We only agree firmly on the fifth conclusion: uncertainty strongly dominates unobserved heterogeneity. However, it is not highest for the lowest level of education but for the highest.

The deviations between original and replication are very substantial for an attempt at pure replication. However, our attempt was frustrated by several barriers. First, when following Chen's instructions we were unable to arrive at the same sample: ours had a larger share of lower educated individuals and came from poorer socioeconomic background. Second, because of restrictions on data accessibility to nonAmericans we were unable to use the same instrument for schooling as Chen did. To 
what extent these problems are responsible for the deviations we cannot assess. We can only note that our instrument performed quite well. We have shown our instrument to be relevant and even though we could not test for its validity, we have no theoretical reason to doubt it. We have also been very careful in checking the correctness of our estimation routine by running Monte Carlo simulations; our program passed this test with flying colors.

We have performed, in Hamermesh's terms, three scientific replications: on women in the same data source as the original paper and on data for the UK and for Germany. The result for US women are closer to our results for men than to Chen's results. Potential inequality is again smaller than observed inequality, the transitory component is very small and much smaller than the permanent component, observed and potential inequality are increasing in education, the correlation coefficients are small (except for high school drop-outs), one of them is negative while the other three are positive and as for men in our estimates, uncertainty dominates over negligible heterogeneity and is increasing in education.

For the UK we find that potential inequality is greater than observed inequality in half the cases and smaller in the other half, both are declining in level of education, the transitory component is only a fraction of the permanent component, the correlation coefficient is not negligible, twice it is negative and in four cases it is positive, uncertainty dominates over heterogeneity with one exception and is declining in education.

In the German case, we found correlation coefficients close to or even larger than 1. This leads to results we find unacceptable and we conclude that the Chen model simply does not apply to our German data.

If we take the results at face value, we can only conclude that the results differ substantially among countries. This suggests that different schooling systems and different labour markets have very different effects on the components of inequality and in particular on the relationship between uncertainty and schooling level. We cannot conclude that a college education is universally a safer investment than a secondary education: in our estimates for the US, both for men and for women, planning a college education carries more uncertainty than planning a high school education, while in the UK, the uncertainty of a college education is lower than the uncertainty of A levels. It would be interesting to investigate which institutional factors drive these results, but that exceeds the purpose of the present project. 
The question is of course whether we can take the results at face value. Our replication of Chen's results shows, at the very least, that different instruments for education give rise to very different results. This does not build confidence in the robustness or general validity of the outcomes. The results for Germany, with correlation coefficients above 1 , even raise more doubts. So we end with the usual certainty: more work is needed. While indeed Chen's model represented a significant step forward towards distinguishing heterogeneity and risk, we think that it's validity can be extended by allowing for non-parametric estimation. This, indeed, will be our next step.

\section{References}

Acemoglu D. (2002), "Technical Change, Inequality, and the Labor Market", Journal of Economic Literature, 40(1): 7-72.

Angrist J.D. and Krueger A.B. (1991), "Does Compulsory School Attendance Affect Schooling and Earnings?", Quarterly Journal of Economics, 106(4): 979-1014.

Arkes J. (2010), "Using unemployment rates as instruments to estimate returns to schooling.", Southern Economic Journal, 76(3): 711-722.

Belzil C. and Leonardi M. (2007), "Risk Aversion and Schooling Decision”, IZA Discussion Paper N.2994, August.

Bonin H., Dohmen T., Falk A., Huffman D. and Sunde U., (2007), "Cross-Sectional Earnings Risk and Occupational Sorting: The Role of Risk Attitudes", Labour Economics, 14(6): 926-937.

Cameron A.C. and Trivedi P.K. (2005), Microeconometrics: methods and applications, Cambridge University Press, Cambridge.

Cameron S.V. and Taber C. (2004), "Estimation of Educational Borrowing Constraint Using Returns to Schooling", Journal of Political Economy, 112(1): 132-182.

Chen S.H. (2008), "Estimating the Variance of Wages in the Presence of Selection and Unobserved Heterogeneity", The Review of Economics and Statistics, 90(2): 275-289.

Connelly R. (1992), "The Effect of Child Care Costs on Married Women's Labor Force Participation", The Review of Economics and Statistics, 74(1): 83-90.

Cunha F., Heckman J.J. and Navarro S. (2005), "Separating Uncertainty from Heterogeneity in Life Cycle Earnings", Oxford Economic Papers, 57(2): 191-261. 
Cunha, F. and J. Heckman (2007), Identifying and estimating the distributions of ex post and ex ante returns to schooling, Labour Economics, Special issue: Education and risk, 14 (6), 870-893

Diaz Serrano, L. (2005), "On the negative relationship between labor income uncertainty and homeownership: risk aversion versus credit constraints", Journal of Housing, 14 (2), 109-126

Eurydice (2008), "Organisation of the education system in Germany 2007/2008".

Griliches Z. (1977), "Estimating the Returns to Schooling: Some Econometric Problems", Econometrica, 45: 1-22.

Hartog, J. (2011), “A Risk Augmented Mincer earnings equation? Taking stock”, Research in Labor Economics, forthcoming.

Hartog, J. and L. Diaz Serrano (2007), "Earnings risk and demand for higher education", Journal of Applied Economics, X (1), 1-28

Hartog, J., H. van Ophem and S. Bajdechi (2004), How risky is investment in human capital?, CESifo Working Paper 1261

Hausman J.A. and Taylor W.E. (1981), "Panel Data and Unobservable Individual Effects", Econometrica, 49(6): 1377-1398.

Hamermesh, D.S. (2007), Replication in Economics, NBER Working Paper Series, W13026.

Heckman J.J. (1979), "Sample Selection Bias as a Specification Error", Econometrica, 47(1): 153-161.

King A.G. (1974), “Occupational Choice, Risk Aversion and Wealth", Industrial and Labor Relations Review, 27(4): 586-596.

Lemieux T. (2006), "Increasing Residual Wage Inequality: Composition Effects, Noisy Data, or Rising Demand for Skill”, American Economic Review, 96(3): 1-64.

Levhari D. and Weiss Y. (1974), "The Effect of Risk on the Investment in Human Capital", American Economic Review, 64(6): 950-963.

McGoldrick K. and Robst J. (1996), "The Effect of Worker Mobility on Compensating Wages for Earnings Risk”, Applied Economics, 28(2): 221-232.

Palacio-Huerta I. (2003), "An Empirical Analysis of the Risk Properties of Human Capital Returns", American Economic Review, 93(3): 948-964.

Raita, S. (2005), The risk of investment in human capital, Amsterdam: Tinbergen Institute Research Series 365

Shaw K.L. (1996), “An Empirical Analysis of Risk Aversion and Income Growth", Journal of Labor Economics, 14(4): 626-653. 
Snow A. and Warren R.S. (1990), "Human Capital Investments and Labor Supply under Uncertainty", International Economic Review, 31(1): 195-206.

Spence M. (1973), “Job Market Signaling”, Quarterly Journal of Economics, 87: 355374

Spence M. (1976), "Competition in Salaries, Credentials and Signaling Prerequisites for Jobs”, Quarterly Journal of Economics, 90: 51-74. 